(2) Open Access Full Text Article

\title{
Assessing the incremental benefit of an extended duration lifestyle intervention for the components of the metabolic syndrome
}

This article was published in the following Dove Press journal:

Diabetes, Metabolic Syndrome and Obesity:Targets and Therapy I June 2016

Number of times this article has been viewed

\author{
Patrick Walden \\ Qingmei Jiang \\ Elizabeth A Jackson \\ Elif A Oral \\ Martha S Weintraub \\ Melvyn Rubenfire \\ Division of Cardiovascular Medicine, \\ Cardiovascular Medicine at Domino's \\ Farms, University of Michigan Health \\ System, Ann Arbor, MI, USA
}

Background: Lifestyle interventions targeting the components of the metabolic syndrome (MetSyn) have been demonstrated to be a cost-effective and suitable treatment strategy for reducing one's risk of developing coronary artery disease and diabetes. The optimal duration has not yet been defined. We sought to evaluate the incremental benefit of extending a lifestyle intervention from 3 months to 6 months.

Methods: We evaluated 114 participants with at least three criteria for the MetSyn in a physicianreferred 6-month lifestyle intervention between August 2008 and December 2012. Baseline and follow-up physiological, biochemical, and anthropometric data were analyzed for mean change and incremental change at each time point.

Results: The mean age at enrollment was $53.0 \pm 10.2$ years, and $42 \%$ of participants were males. The mean body mass index at enrollment was $38.2 \pm 0.86 \mathrm{~kg} / \mathrm{m}^{2}$ for males and $38.6 \pm 0.93 \mathrm{~kg} / \mathrm{m}^{2}$ for females. Anthropometric measures associated with weight management (body mass index, weight, and body fat percentage) improved significantly with the additional 3-month intervention $(P<0.001)$. Systolic blood pressure $(P=0.0001)$ and diastolic blood pressure $(P=0.00006)$ and triglycerides, fasting blood glucose, and homeostatic model assessment of insulin resistance in diabetic participants ( $P=0.006, P=0.004, P=0.01$, respectively) improved rapidly in the initial 3 -month intervention without incremental benefit of the additional 3 months. Improvements in fasting insulin $(P=0.01)$ and homeostatic model assessment of insulin resistance $(P=0.02)$ for nondiabetic participants required the full 6-month intervention before significant reductions were achieved.

Conclusion: A 6-month lifestyle intervention yielded significantly better results for variables related to weight management. Standard physiological measures for the MetSyn respond rapidly in a 3-month lifestyle intervention. The long-term impact of an increased duration lifestyle intervention remains to be seen.

Keywords: lifestyle intervention, metabolic syndrome, diabetes

\section{Introduction}

The cluster of cardiometabolic risk factors known as the metabolic syndrome (MetSyn) continues to gain importance, despite the controversy surrounding whether this entity should be a distinct diagnosis. Adults with the MetSyn are approximately two times more likely to develop cardiovascular disease ${ }^{1,2}$ and 3.5-5 times more likely to develop diabetes. ${ }^{3}$ In 2010, the age-adjusted prevalence of the MetSyn in adults older than 20 years was $>20 \%$ of the population. ${ }^{4}$ The relationship between obesity, particularly central obesity, and the individual components of the MetSyn is well documented and will continue to be the focus of future public health initiatives, especially, considering
Correspondence: Melvyn Rubenfire Division of Cardiovascular Medicine, Cardiovascular Medicine at Domino's Farms, University of Michigan Health System, 24 Frank Lloyd Wright Drive, Suite A3700, Ann Arbor, MI 480 I6, USA Tel + I 73499874 II

Email mrubenfi@med.umich.edu
Diabetes, Metabolic Syndrome and Obesity:Targets and Therapy 2016:9 I77-184 (c) (1) (5) 2016 Walden et al. This work is published and licensed by Dove Medical Press Limited. The full terms of this license are available at https://www.dovepress.com/terms. cc. you hereby accept the Terms. Non-commercial uses of the work are permitted without any further permission from Dove Medical Press Limited, provided the work is properly attributed. For

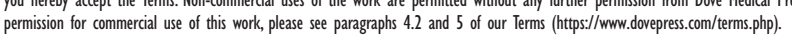


that the rates of overweight and obesity have nearly doubled in the past 40 years. ${ }^{5}$ The Diabetes Prevention Program conducted over 4 years demonstrated that an intense lifestyle intervention can reduce the prevalence and onset of diabetes in prediabetes. When compared to an active control group, there was a 58\% reduction in incident diabetes associated with lifestyle modification compared to a $31 \%$ reduction in those treated with metformin. ${ }^{6}$ While the results were surprisingly robust, the cost of the program and willingness and ability of individuals to participate and comply in the clinical setting have not been tested. We demonstrated that a 3-month lifestyle modification program using the existing resources of cardiac rehabilitation can improve individual components in men and women with three or more of the factors at baseline. ${ }^{7}$ The Mayo Clinic recently reported similar findings in this setting and concluded that it is a cost-effective approach for managing the MetSyn. ${ }^{8}$

The ideal program duration has yet to be identified, but our pilot 3-month program evolved into a 6-month program with the encouragement of the participants and staff, who felt it would affect the efficacy and long-term compliance with behavioral change. We report herein the outcomes for participants completing a 6-month program to assess if there is an incremental benefit over a 3-month lifestyle intervention. We hypothesized that a longer program would be feasible for participants with incremental improvement in MetSyn parameters over time. The findings have both clinical and economic importance.

\section{Methods}

The University of Michigan Health System's Metabolic Fitness Program (MetFit) targeting the MetSyn in the cardiac rehabilitation setting began enrollment in 2005. Participants were referred by physicians and were aware of the outcomes of the research conducted. Written informed consent was obtained from all participants. Ethics approval was regulated by the University of Michigan Medical School Institutional Review Board (HUM0045929).

Methods and results of the 3-month program, including enrollment procedure, program content, and costs, have been previously reported. ${ }^{7}$ The methods for this report are the same but for changes described in following sections. Briefly, all participants who were referred and presented with at least three components of the MetSyn were included. The assessment was obtained by a trained nurse practitioner, including a baseline medical history from the patient and electronic medical records; fasting laboratory tests; and weight, waist, blood pressure (BP), and symptom limited exercise test using standards of American Heart Association. ${ }^{9}$ The validated nine-item Patient Health Questionnaire (PHQ-9) tool was used to assess for depressive symptoms. ${ }^{10}$

\section{Program duration and cost for the 6-month program}

The program duration was 24 weeks, and each weekly session was 90 minutes long. A brief midpoint evaluation including repeat of baseline laboratory tests was performed by the nurse practitioner, and a formal progress report was mailed to the referring physician and the patient. Prior to the conclusion of the program, the baseline evaluation was repeated and a formal exit letter was sent to the referring physician and patient that included the change from baseline measures and recommendation for continuing lifestyle and medication changes. The patient cost for the 6-month program was $\$ 700$, paid prior to the first session, and was refunded only for medical reasons. The clinical and laboratory patient assessments were billed to the third-party payer.

\section{Exercise content and monitoring}

Recommendations for exercise included progression from 150 minutes/wk to 300 minutes/wk of a combination of moderate and vigorous intensity aerobic activity. ${ }^{11}$ Aerobic exercise intensity was prescribed using heart rate data from entry graded exercise testing data with targets $60 \%-85 \%$ of heart rate reserve formula. When graded exercise testing was not indicated, or not available, Borg ratings of perceived exertion scale was used targeting exertion levels from 11 (fairly light) to 13 (somewhat hard). Some lowrisk participants were allowed to exercise to intensities of 15 (hard) on the Borg ratings of perceived exertion scale. Additionally, a full-body strengthening program (free weight, resistance bands, or combination circuit training) was recommended minimum two times weekly targeting all major muscle groups (legs, chest, back, shoulders, core, biceps, and triceps).

\section{Nutrition content and monitoring}

Mediterranean eating patterns, adapted for an American diet, were encouraged for all participants. This included a low glycemic index meal plan high in vegetables, legumes, fruits, fish, whole grains, nuts, and olive oil and low in red meat and high fat dairy. Following the initial evaluation, personalized energy intake guidelines were calculated by our registered dietitian, as estimated by the Mifflin-St Jeor equation based on sex, age, height, weight, and activity level. ${ }^{12}$ Resting energy equivalent as determined by the Mifflin-St Jeor equation was multiplied by an activity factor of 1.3 for participants who fully participated in the exercise portion of the 
program. For less active participants, an activity factor of 1.2 was recommended to estimate energy needs.

Over the course of 24 weeks, members participated in 12 nutrition classes and group discussions. Individual nutrition consultations were not included in the program; however, they were encouraged (either with insurance coverage or at the expense of the participant) for patients struggling to improve their eating pattern.

Consistency with a Mediterranean eating pattern was evaluated at the 3-month and 6-month evaluations with a brief food frequency tool developed for the program. This was a 15-question assessment of the inclusion of the Mediterranean diet components mentioned earlier, adapted from the Prevención con Dieta Mediterránea (PREDIMED) research. ${ }^{13}$

\section{Statistical methods}

To compare differences in continuous physiology measures from baseline to 3 months, baseline to 6 months, and 3 months to 6 months, repeated-measures analysis of variance was used because of its capability of handling missing values. Autoregressive first order was selected for heterogeneous covariance structure. The least-square estimate was used for calculating the mean at baseline, 3 months, and 6 months. Bonferroni correction was used to adjust for multiple comparisons. A $P$-value of $<0.05$ was used to determine statistical significance. Data were analyzed using SAS 9.3 (SAS Institute Inc., Cary, NC, USA), and repeated-measures analysis of variance was conducted using SAS's PROC MIXED.

\section{Results}

Patients (N=114) with MetSyn were enrolled in the 6-month program between August 2008 and December 2012. Table 1 describes the baseline demographics, biometrics, laboratory assays, and results of the intervention. The mean age of patients was $53.0 \pm 10.2$ years (range: $24-80$ years), $58 \%$ were women, and $90.4 \%$ were White. Using body mass

Table I Baseline characteristics of metabolic fitness participants

\begin{tabular}{|c|c|c|c|c|c|c|}
\hline \multirow[t]{2}{*}{ Characteristic } & \multicolumn{3}{|c|}{ Least-square mean \pm standard error } & \multicolumn{3}{|l|}{$P$-values } \\
\hline & $\begin{array}{l}\text { BL } \\
(n=|| 4)\end{array}$ & $\begin{array}{l}3 \text { months } \\
(n=107)\end{array}$ & $\begin{array}{l}6 \text { months } \\
(n=90)\end{array}$ & $\begin{array}{l}\text { BL to } \\
3 \text { months }\end{array}$ & $\begin{array}{l}\text { BL to } \\
6 \text { months }\end{array}$ & 3-6 months \\
\hline Age, years & $53.0 \pm 10.2$ & $53.2 \pm 10.0$ & $53.4 \pm 10.3$ & & & \\
\hline Sex, $M$ & $48(42 \%)$ & $44(41 \%)$ & $37(4 \mid \%)$ & & & \\
\hline $\mathrm{BMI}(\mathrm{M}), \mathrm{kg} / \mathrm{m}^{2}$ & $38.2 \pm 0.86$ & $36.8 \pm 0.81$ & $35.7 \pm 0.75$ & $<0.0001$ & $<0.0001$ & $<0.0001$ \\
\hline $\mathrm{BMI}(\mathrm{F}), \mathrm{kg} / \mathrm{m}^{2}$ & $38.6 \pm 0.93$ & $37.5 \pm 0.90$ & $36.8 \pm 0.91$ & $<0.0001$ & $<0.0001$ & $<0.0001$ \\
\hline Weight (M), kg & $126.1 \pm 22.3$ & $121.6 \pm 21.5$ & $115.5 \pm 17.4$ & $<0.0001$ & $<0.0001$ & $<0.0005$ \\
\hline Weight (F), kg & $103.6 \pm 20.3$ & $100.8 \pm 20.0$ & $98.6 \pm 20.0$ & $<0.0001$ & $<0.0001$ & $<0.0001$ \\
\hline Waist (M), cm & $120.8 \pm 14.0$ & $120.3 \pm 13.9$ & $1 \mid 7.1 \pm 12.7$ & $<0.0001$ & $<0.0001$ & 0.2 \\
\hline Waist (F), cm & 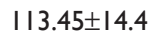 & $109.6 \pm 13.2$ & $106.6 \pm 13.9$ & $<0.0001$ & $<0.0001$ & 0.047 \\
\hline Body fat (\%) & $44.0 \pm 0.73$ & $42.8 \pm 0.75$ & $41.8 \pm 0.79$ & $<0.0001$ & $<0.0001$ & $<0.0001$ \\
\hline Systolic BP, mmHg & $122.4 \pm 1.49$ & $\mathrm{I} \mid 7.4 \pm \mathrm{I} .47$ & $118.5 \pm 1.33$ & 0.001 & 0.04 & I \\
\hline Diastolic BP, mmHg & $73.6 \pm 0.91$ & $70.8 \pm 0.80$ & $70.1 \pm 0.82$ & 0.008 & 0.0004 & I \\
\hline Total cholesterol, mg/dL & $186.6 \pm 3.64$ & $177.1 \pm 3.42$ & $174.7 \pm 3.49$ & 0.002 & $<0.0001$ & 0.9 \\
\hline Triglycerides, mg/dL & $212.2 \pm 10.36$ & $180.9 \pm 8.88$ & $172.9 \pm 9.72$ & 0.0002 & $<0.0001$ & 0.9 \\
\hline Triglycerides (DM), mg/dL & $232.2 \pm 17.88$ & $186.8 \pm 15.58$ & $|76.7 \pm| 6.6 \mid$ & 0.0006 & $<0.0001$ & I \\
\hline Triglycerides (not DM), mg/dL & $193.5 \pm 10.68$ & $174.9 \pm 9.15$ & $167.3 \pm 10.78$ & 0.2 & 0.06 & 1 \\
\hline LDL-C, mg/dL & $101.9 \pm 3.00$ & $98.1 \pm 2.88$ & $98.0 \pm 2.88$ & 0.3 & 0.3 & 1 \\
\hline HDL-C (M), mg/dL & $37.9 \pm 1.10$ & $38.8 \pm 1.38$ & $39.0 \pm 1.30$ & 0.8 & 0.8 & 1 \\
\hline HDL-C (F), mg/dL & $48.0 \pm 1.41$ & $47.0 \pm 1.23$ & $46.9 \pm 1.39$ & 0.8 & 0.8 & 1 \\
\hline Fasting glucose, mg/dL & $130.1 \pm 4.67$ & $118.7 \pm 3.38$ & $115.8 \pm 3.35$ & 0.003 & 0.0003 & 0.6 \\
\hline Fasting glucose (DM), mg/dL & $|6| .1 \pm 7.69$ & $139.2 \pm 5.79$ & $|32.8 \pm 6.5|$ & 0.004 & 0.0008 & 0.7 \\
\hline Fasting glucose (not DM), mg/dL & $101.1 \pm 1.01$ & $99.9 \pm 1.23$ & $100.0 \pm 1.15$ & 0.8 & 1 & 1 \\
\hline Fasting insulin, $\mu \mathrm{M} / \mathrm{mL}$ & $19.0 \pm 1.00$ & $16.6 \pm 0.99$ & $14.9 \pm 0.88$ & 0.053 & $<0.0001$ & 0.09 \\
\hline Fasting insulin (DM), $\mu \mathrm{M} / \mathrm{mL}$ & $21.6 \pm 1.63$ & $18.6 \pm 2.00$ & $|6.4 \pm 1.6|$ & 0.4 & 0.01 & 0.3 \\
\hline Fasting insulin (not DM), $\mu \mathrm{M} / \mathrm{mL}$ & $17.3 \pm 1.24$ & $15.6 \pm 1.07$ & $14.1 \pm 1.05$ & 0.4 & 0.01 & 0.4 \\
\hline hs-CRP & $6.4 \pm 0.61$ & $5.3 \pm 0.51$ & $5.4 \pm 0.64$ & 0.02 & 0.2 & I \\
\hline HOMA-IR, mU·mmol/L² & $5.6 \pm 0.33$ & $4.6 \pm 0.33$ & $4.0 \pm 0.27$ & 0.01 & $<0.0001$ & 0.06 \\
\hline HOMA-IR (DM), $\mathrm{mU} \cdot \mathrm{mmol} / \mathrm{L}^{2}$ & $7.5 \pm 0.55$ & $5.9 \pm 0.73$ & $4.9 \pm 0.58$ & 0.09 & 0.002 & 0.2 \\
\hline HOMA-IR (not DM) & $4.3 \pm 0.31$ & $3.9 \pm 0.28$ & $3.5 \pm 0.28$ & 0.4 & 0.02 & 0.6 \\
\hline Depression score & $5.9 \pm 0.45$ & $3.0 \pm 0.33$ & $2.8 \pm 0.40$ & $<0.0001$ & $<0.0001$ & I \\
\hline
\end{tabular}

Abbreviations: BL, baseline; M, male; BMI, body mass index; F, female; BP, blood pressure; DM, diabetes mellitus; LDL-C, low-density lipoprotein cholesterol; HDL-C, high-density lipoprotein cholesterol; hs-CRP, high-sensitivity C-reactive protein; HOMA-IR, homeostatic model assessment of insulin resistance. 
index (BMI) category, $32(91.2 \%)$ patients were found to be obese and $73(64.0 \%)$ were morbidly obese. Based on the American Heart Association/National Cholesterol Education Program - Adult Treatment Panel III definitions for the MetSyn, 93 (81.6\%) patients had hypertension, 95 (83.3\%) impaired fasting glucose, 111 (97.4\%) abdominal obesity, 80 (70.2\%) elevated fasting triglycerides, and 78 (68.4\%) a low high-density lipoprotein cholesterol. Coronary artery disease was present in seven $(6.1 \%)$ patients and diabetes mellitus in $55(48.0 \%)$ patients. One $(<1 \%)$ patient reported smoking.

Of the 114 patients enrolled in the 6-month program, 107 (93.9\%) were available for the midpoint evaluation and $90(78.9 \%)$ for the final evaluation. Seven participants $(6.1 \%)$ were dropouts at 3 months with a total of $24(21.1 \%)$ by the completion of the 6-month program. Of those who completed the entire program, $67(63.2 \%)$ completed $75 \%$ of the exercise and education sessions. There was no relationship between the number of sessions attended and change in the measured variables by Pearson's and Spearman's correlation.

Incremental weight loss from baseline to 3 months and to 6 months was modest but highly significant for both men and women (Table 1). Twenty-nine patients $(27 \%)$ lost $5 \%$ and five $(4.5 \%)$ lost $10 \%$ of body weight at the midpoint evaluation, whereas at 6 months, $48.9 \%$ had lost $5 \%$ and $15.6 \%$ lost $10 \%$ of body weight. Weight loss was enhanced by a greater percentage of initial body weight in men at both time points. The mean change at 6 months for men was $-8.71 \pm 8.03 \mathrm{~kg}, 95 \% \mathrm{CI}(-11.34,-6.03)$, and for women $-4.85 \pm 4.54 \mathrm{~kg}, 95 \%$ CI $(-6.08,-3.58)$, with $P=0.01$ for each. The mean change in body fat percentage was greater in men though not significant $(P=0.1)$.
Significant reductions in waist circumference were observed in men at 3 -month and 6-month evaluations $(P<0.0001)$ with further reduction between 3 months and 6 months $(P<0.047)$. The change in waist measurement of men was also significant at each time point $(P<0.0001)$, though the change observed between 3 months and 6 months was not significant $(P=0.2)$. The reduction in body fat percentage (Model TBF-310; Tanita, Arlington Heights, IL, USA) and BMI is demonstrated in Table 1. There was no correlation between baseline BMI or body fat percentage and reduction at program completion.

Highly relevant reductions in systolic BP and diastolic BP were present at 3 months, but the additional 3 months yielded no additional benefit (Figure 1). Table 2 summarizes the baseline and follow-up medication profile. Improved BP occurred despite significant decrease in use of diuretics and angiotensin-converting-enzyme inhibitors/angiotensin receptor blockers at 3 months (changes made by primary care physician). Fasting blood glucose (FBG) and triglycerides responded differently in nondiabetics as compared with noninsulin-dependent diabetics (Table 1 and Figure 1). There was no change in FBG in the nondiabetics. The magnitude of decrease in triglycerides from baseline to 3 months in nondiabetics was not significant, while the change from baseline to 6 months was robust $(-30 \%, P=0.06)$. The noninsulin-dependent diabetics had a significant reduction in triglycerides and glucose concentrations at 3 months, and these reductions were sustained through 6 months. The incremental reductions in FBG associated with participating in the additional 3 months were not significant, possibly due to the decrease in the use of oral hypoglycemic therapies (3 months $26.3 \%$ vs 6 months $19.3 \%, P=0.03$ ). There were

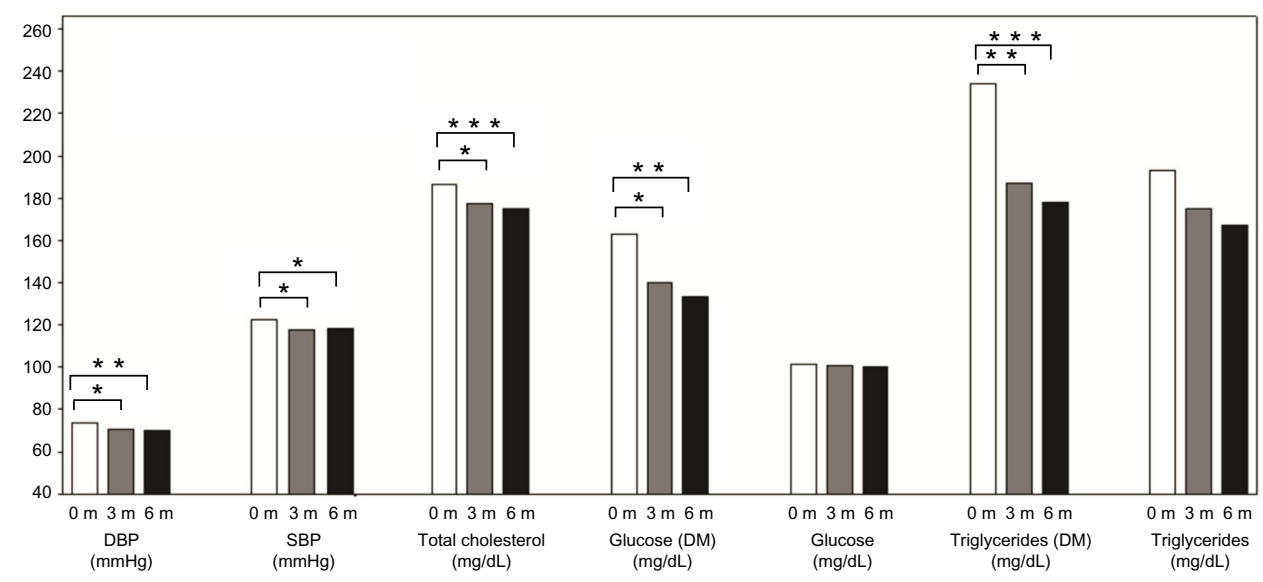

Figure I Change in characteristics throughout the time course.

Notes: $* P$-value in $0.001-0.05$. $* * P$-value in $0.0001-0.001$. $* * * P$-value $<0.0001$.

Abbreviations: m, months; DBP, diastolic blood pressure; SBP, systolic blood pressure; DM, diabetes mellitus. 
Table 2 Medication profile

\begin{tabular}{|c|c|c|c|c|c|c|}
\hline \multirow[t]{2}{*}{ Medication } & \multirow{2}{*}{$\begin{array}{l}\text { BL, } \\
\text { n (\%) }\end{array}$} & \multirow{2}{*}{$\begin{array}{l}3 \text { months, } \\
\text { n (\%) }\end{array}$} & \multirow{2}{*}{$\begin{array}{l}6 \text { months, } \\
\text { n (\%) }\end{array}$} & BL to 3 months & BL to 6 months & 3-6 months \\
\hline & & & & \multicolumn{3}{|l|}{$P$-value } \\
\hline Antiplatelet & 49 (43.0) & $44(38.6)$ & $34(29.8)$ & - & 0.0003 & 0.008 \\
\hline Diuretic & $23(20.2)$ & $21(18.4)$ & $18(15.8)$ & - & 0.03 & - \\
\hline ACEi or ARB & $50(43.9)$ & $46(40.4)$ & $42(36.8)$ & - & 0.03 & - \\
\hline Hypoglycemic & $29(25.4)$ & $30(26.3)$ & $22(19.3)$ & - & - & 0.03 \\
\hline
\end{tabular}

Abbreviations: $\mathrm{BL}$, baseline; $\mathrm{ACEi}$, angiotensin-converting-enzyme inhibitor; $\mathrm{ARB}$, angiotensin receptor blocker.

no improvements in high-density lipoprotein cholesterol and low-density lipoprotein cholesterol. The fasting insulin decreased significantly in both noninsulin-dependent diabetic participants and nondiabetic participants at 6 months. While the homeostatic model assessment of insulin resistance (HOMA-IR) reductions (Table 1 and Figure 2) was significant at each time point in noninsulin-dependent diabetics, the nondiabetic group required 6 months to reach significance $(P=0.02)$.

The mean PHQ-9 score was 5.9 \pm 0.45 at baseline (no evidence of depression $<5$ ). Based upon the PHQ-9 depression scoring, ${ }^{10}$ moderate depression (PHQ-9 score $>9-14$ ) was present in 17 (15\%) participants and a major depressive disorder (score >14) in six (5.3\%) participants at baseline. The initial reduction in the PHQ-9 depression index at baseline continued to 6 months though the incremental change from 3 months to 6 months was not significant. Mild-to-moderate depressive symptoms (PHQ-9 scores 5-14) were present in $38.9 \%$ of participants at baseline and were reduced to $12.3 \%$ of participants at 3 months and $5.3 \%$ of participants at 6 months, $P$-values $=0.03$ by McNemar's test. The highsensitivity C-reactive protein was elevated at baseline and decreased significantly at 3 months $(6.4 \pm 0.61 \mathrm{mg} / \mathrm{dL}$ vs $5.3 \pm 0.51 \mathrm{mg} / \mathrm{dL} ; P=0.02)$.
The change in the number of cardiometabolic risk factors from baseline to 3 months and 6 months is summarized in Table 3. Upon completion of the 6-month program, $28 \%$ of participants had eliminated one criterion, $52 \%$ eliminated at least one criterion, $24 \%$ eliminated at least two criteria, and $3.3 \%$ eliminated three or more criteria (Table 3 ). At the midpoint evaluation, 14\% (16/114) no longer fulfilled criteria for MetSyn, which is similar to $19 \%$ in the initial publication of the 12-week program. ${ }^{7}$ At the 6-month program completion, $34.2 \%$ of participants no longer fulfilled criteria for the MetSyn.

\section{Discussion}

We extended our 3-month MetFit to a 6-month format at the suggestion of the participants with the hypothesis that there would be incremental benefit, but were concerned about how this would affect program completion. ${ }^{14}$ The challenges of lifestyle adherence are well documented, and optimal program design or duration has not been identified. Approximately $30 \%$ of participants in this observation report were included in our initial work.

The physiological and psychological parameters of the MetSyn generally responded very quickly to lifestyle changes. There was a clear benefit at both the 3-month and

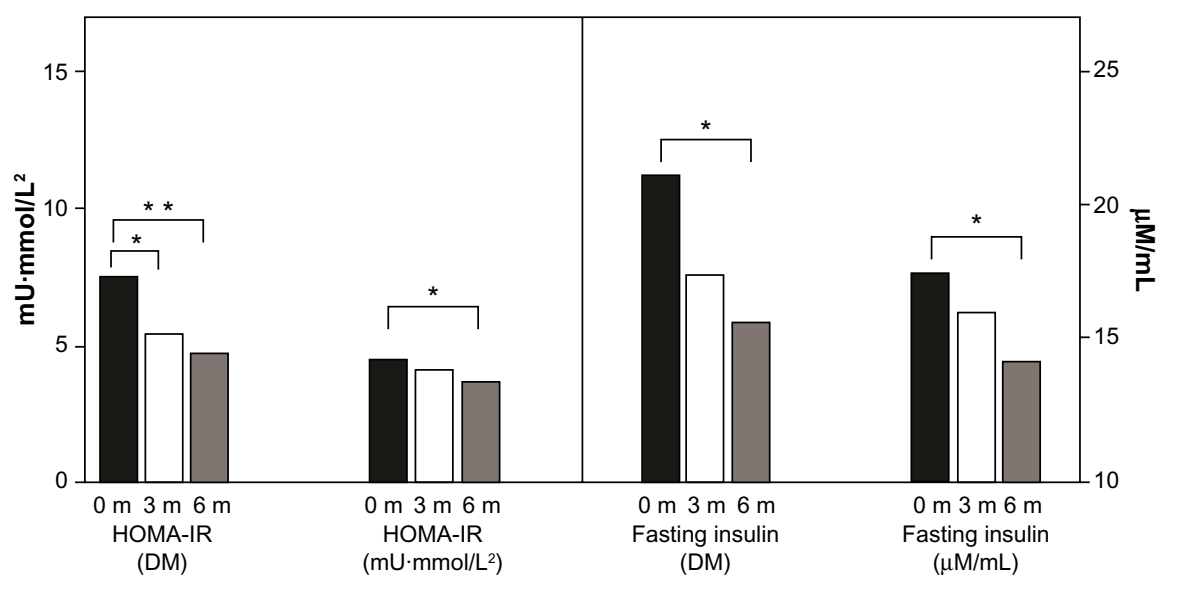

Figure 2 Change in characteristics associated with insulin resistance.

Notes: $* P$-value in $0.00 \mathrm{I}-0.05$. ${ }^{*}{ }^{*}$-value in $0.000 \mathrm{I}-0.00 \mathrm{I}$.

Abbreviations: m, month(s); HOMA-IR, homeostatic model assessment of insulin resistance; DM, diabetes mellitus. 
Table 3 Clinical criteria change

\begin{tabular}{llll}
\hline $\begin{array}{l}\text { Change in the number } \\
\text { of metabolic syndrome } \\
\text { criterion }\end{array}$ & $\begin{array}{l}\text { BL to } \\
\mathbf{3} \text { months, } \\
\mathbf{n}(\%)\end{array}$ & $\begin{array}{l}\text { BL to } \\
\mathbf{6} \text { months, } \\
\mathbf{n}(\%)\end{array}$ & $\begin{array}{l}\mathbf{3 - 6} \\
\text { months, } \\
\mathbf{n}(\%)\end{array}$ \\
\hline Gained two & $2(1.9)$ & $\mathrm{I}(1 . \mathrm{I})$ & $\mathrm{I}(\mathrm{I} . \mathrm{I})$ \\
Gained one & $15(14.0)$ & $7(7.8)$ & $9(10.0)$ \\
No change & $60(56.1)$ & $42(47)$ & $48(53.9)$ \\
Lost one & $21(19.6)$ & $25(27.8)$ & $23(25.8)$ \\
Lost two & $9(8.4)$ & $19(21.1)$ & $6(6.7)$ \\
Lost three & $0(0)$ & $2(2.2)$ & $0(0)$ \\
Lost four & $0(0)$ & $1(1.1)$ & $2(2.3)$ \\
\hline
\end{tabular}

Abbreviation: BL, baseline.

6-month time points for the components of the MetSyn, the HOMA-IR as a measure of insulin resistance, and the high-sensitivity $\mathrm{C}$-reactive protein as a measure of systemic inflammation. There was minimal correlation between change in weight, BP, glucose, and triglycerides over time, which may be related to the protocol that encouraged the primary care physician to adjust medication as warranted. This was particularly evident in the reduction in the use of dosing of antihypertensive agents, hypoglycemics, and diuretics (Table 2). The improvement in insulin resistance appeared to be regulated by how much insulin resistance there was at baseline and the presence of diabetes. Both may be influenced by the genetic predisposition or endogenous factors, such as age and metabolic flexibility with exercise. The large variability of these factors may also play a role in the observed findings. In addition, overall insulin resistance is affected by both muscle glucose uptake and hepatic response to insulin suppression. A more sensitive method (such as an oral glucose tolerance test with isotope infusion or insulin clamp) may have helped to uncover continuous improvement in muscle insulin resistance but exceeded the scope of this study. We are interested in pursuing deep mechanistic studies in our future cohorts. The incremental benefit from the additional 3 months was primarily in weight, BMI, and body fat. This supports well-documented evidence regarding the challenges of weight management and long-term weight maintenance. We were surprised to find no relationship between baseline BMI and body fat and outcome at 3 months or 6 months. The diabetic cohort had a highly significant decrease in FBG despite the reduction in the use of hypoglycemic drugs. There was also a reduction in fasting insulin at 6 months coupled with a decrease in HOMA-IR. The nondiabetics had no change in fasting blood glucose, but the reduction in insulin at 6 months was associated with a significant reduction in HOMA-IR. Similarly, the magnitude of reduction in triglycerides was significantly greater in the diabetics.
The assumption that all parameters would benefit from additional 3 months participation in a lifestyle enhancement was not supported, though long-term follow-up is needed to accurately understand the value of increased duration of lifestyle interventions. The findings stress the importance of continued engagement and participation in lifestyle programming for weight management purposes.

Reducing the number of metabolic risk factors with lifestyle intervention has the potential to have a major impact on otherwise healthy persons and the cost of health care. The prevalence and severity of coronary artery disease when controlled for a number of metabolic risk factors, diabetes, and insulin requirement increases across the spectrum from $51 \%$ for nondiabetics with less than three cardiometabolic risk factors to $60 \%$ among nondiabetics with three or more cardiometabolic risks, to $71 \%$ among diabetics not requiring insulin, and to $80 \%$ among diabetics requiring insulin. ${ }^{15}$

The results of our study are not readily comparable to other observational or controlled studies of lifestyle interventions for high-risk cohorts and the MetSyn for a number of reasons: the variable duration of onsite supervision, differences in nutrition and exercise recommendations, and most importantly, a much greater percentage of morbidly obese by BMI category and $100 \%$ prevalence of the MetSyn in our study. ${ }^{8,16-19}$ There are several limitations for the comparison of our 3-month and 6-month programs to one another and other studies. We did not seek to replicate the Diabetes Prevention Program due to the intensity and cost of the intervention. We did hope to demonstrate that a program targeting lifestyle could be adapted for the clinical setting of cardiac rehabilitation program using existing clinical resources. However, a true cost analysis and comparison have not been completed and will be the focus of future work. The self-pay program charge serves as a self-selection bias. Persons willing and able to pay $\$ 350-\$ 700$ may have higher initial levels of motivation and better education and baseline knowledge and may be more actively engaged than the general population. The lack of a usual care or active control group and randomization diminishes the strength of our observations. Finally, while the distribution is reflective of the population in our health system, the uniform ethnic and socioeconomic distribution reduces the generalizability of the results.

\section{Conclusion}

Compared to the 3-month program, the additional 3 months of participation in MetFit increased the number of participants who no longer had the MetSyn by 2.4 -fold, achieving this goal in approximately one-third of the participants. 
For variables related to weight management (BMI, waist circumference, body weight, and body fat), participation in a 6-month lifestyle program has a significant advantage over a 3-month lifestyle program as did triglycerides, insulin, and HOMA-IR in nondiabetics. Other variables of the MetSyn (hypertension, triglycerides in diabetes, and glucose) respond rapidly in the 3-month format. It remains to be seen if the 6 months of lifestyle intervention translate to greater longterm benefit compared to a 3-month program.

Epidemiological and prospective data support a long-term influence of early metabolic control on clinical outcomes known as metabolic memory. ${ }^{20}$ Improvements over time may have long-lasting microvascular and macrovascular clinical repercussions for cardiovascular health despite indiscernible metabolic states at long-term follow-up. Our study was not designed to evaluate this phenomenon, but we established the feasibility of a lifestyle intervention program using the infrastructure of a cardiac rehabilitation setting in the treatment of MetSyn.

\section{Disclosure}

Patrick Walden, Qingmei Jiang, Martha S Weintraub, and Melvyn Rubenfire report no conflicts of interest in this work. Elizabeth A Jackson was actively involved in research and study selection grant reviews of National Institutes of Health. She has worked as an editor of American Journal of Medicine, as a consultant and an editor in American College of Cardiology, as an expert witness in Motley, Rice LLC, as a consultant and author in UpToDate, as an author in Spry Publishing, as a consultant and lecturer in National Association for Continuing Education, as a co-investigator in Pfizer, Inc., as a consultant in McKesson, and as an editor in Elsevier Publishing. Also, she was involved in the activities of site and research in Pfizer, Inc. Elif A Oral has no conflicts to interest to declare related to the current manuscript. She was an advisor to BMS and Amylin LLC in the past and is currently an advisor to AstraZeneca, Akcea Therapeutics, and Aegerion Pharmaceuticals. Currently, she is receiving grant support from Ionis Pharmaceuticals, GI Dynamics, Aegerion Pharmaceuticals and has received grant support from BMS, Amylin LLC, Eli Lilly, and Novo Nordisk in the past.

\section{References}

1. Gami AS, Witt BJ, Howard DE, et al. Metabolic syndrome and risk of incident cardiovascular events and death: a systematic review and meta-analysis of longitudinal studies. J Am Coll Cardiol. 2007;49(4): 403-414.
2. Mottillo S, Filion KB, Genest J, et al. The metabolic syndrome and cardiovascular risk a systematic review and meta-analysis. $\mathrm{J} \mathrm{Am} \mathrm{Coll}$ Cardiol. 2010;56(14):1113-1132.

3. Ford ES, Li C, Sattar N. Metabolic syndrome and incident diabetes: current state of the evidence. Diabetes Care. 2008;31(9):1898-1904.

4. Beltran-Sanchez H, Harhay MO, Harhay MM, McElligott S. Prevalence and trends of metabolic syndrome in the adult U.S. population, 1999-2010. J Am Coll Cardiol. 2013;62(8):697-703.

5. Lavie CJ, McAuley PA, Church TS, Milani RV, Blair SN. Obesity and cardiovascular diseases: implications regarding fitness, fatness, and severity in the obesity paradox. J Am Coll Cardiol. 2014;63(14): 1345-1354.

6. Knowler WC, Barrett-Connor E, Fowler SE, et al; Diabetes Prevention Program Research Group. Reduction in the incidence of type 2 diabetes with lifestyle intervention or metformin. $N$ Engl J Med. 2002;346(6):393-403.

7. Rubenfire M, Mollo L, Krishnan S, et al. The metabolic fitness program: lifestyle modification for the metabolic syndrome using the resources of cardiac rehabilitation. J Cardiopulm Rehabil Prev. 2011;31(5):282-289.

8. Rodriguez-Escudero JP, Somers VK, Heath AL, et al. Effect of a lifestyle therapy program using cardiac rehabilitation resources on metabolic syndrome components. J Cardiopulm Rehabil Prev. 2013;33(6):360-370.

9. Gibbons RJ, Balady GJ, Beasley JW, et al. ACC/AHA guidelines for exercise testing. A report of the american college of Cardiology/ American heart association task force on practice guidelines (committee on exercise testing). J Am Coll Cardiol. 1997;30(1):260-311.

10. Kroenke K, Spitzer RL, Williams JB. The PHQ-9: validity of a brief depression severity measure. J Gen Intern Med. 2001;16(9):606-613.

11. U.S. Department of Health and Human Services. 2008 Physical Activity Guidelines for Americans. Washington, DC: U.S. Department of Health and Human Services; 2008.

12. Mifflin MD, St Jeor ST, Hill LA, Scott BJ, Daugherty SA, Koh YO. A new predictive equation for resting energy expenditure in healthy individuals. Am J Clin Nutr. 1990;51(2):241-247.

13. Martinez-Gonzalez MA, Fernandez-Jarne E, Serrano-Martinez M, Wright M, Gomez-Gracia E. Development of a short dietary intake questionnaire for the quantitative estimation of adherence to a cardioprotective Mediterranean diet. Eur J Clin Nutr. 2004;58(11): 1550-1552.

14. Davies P, Taylor F, Beswick A, et al. Promoting patient uptake and adherence in cardiac rehabilitation. Cochrane Database Syst Rev. 2010;7:CD007131.

15. Hulten E, Bittencourt MS, O'Leary D, et al. Cardiometabolic risk is associated with atherosclerotic burden and prognosis: results from the partners coronary computed tomography angiography registry. Diabetes Care. 2014;37(2):555-564.

16. Gillies CL, Abrams KR, Lambert PC, et al. Pharmacological and lifestyle interventions to prevent or delay type 2 diabetes in people with impaired glucose tolerance: systematic review and meta-analysis. BMJ. 2007;334(7588):299.

17. Ackermann RT, Finch EA, Brizendine E, Zhou H, Marrero DG. Translating the Diabetes Prevention Program into the community. The DEPLOY Pilot Study. Am J Prev Med. 2008;35(4):357-363.

18. Maruyama C, Kimura M, Okumura H, Hayashi K, Arao T. Effect of a worksite-based intervention program on metabolic parameters in middle-aged male white-collar workers: a randomized controlled trial. Prev Med. 2010;51(1):11-17.

19. Davis SK, Quarells R, Gibbons GH. A comprehensive cardiovascular disease lifestyle treatment controlled trial among high-risk African Americans. Open J Prev Med. 2013;3(9):526-533.

20. Ceriello A. The emerging challenge in diabetes: the "metabolic memory". Vascul Pharmacol. 2012;57(5-6):133-138. 


\section{Publish your work in this journal}

Diabetes, Metabolic Syndrome and Obesity: Targets and Therapy is opinion and commentaries are all considered for publication. The an international, peer-reviewed open-access journal committed to the rapid publication of the latest laboratory and clinical findings in the fields of diabetes, metabolic syndrome and obesity research. Original research, review, case reports, hypothesis formation, expert manuscript management system is completely online and includes a very quick and fair peer-review system, which is all easy to use. Visit $\mathrm{http}: / / \mathrm{www}$.dovepress.com/testimonials.php to read real quotes from published authors.

Submit your manuscript here: http://www.dovepress.com/diabetes-metabolic-syndrome-and-obesity-targets-and-therapy-journal 